\title{
Reasoning versus text processing in the Wason selection task: A nondeontic perspective on perspective effects
}

\author{
AMIT ALMOR \\ University of Southerm California, Los Angeles, California \\ and \\ STEVEN A. SLOMAN \\ Brown University, Providence, Rhode Island
}

\begin{abstract}
We argue that perspective effects in the Wason four-card selection task are a product of the linguistic interpretation of the rule in the context of the problem text and not of the reasoning process underlying card selection. In three experiments, participants recalled the rule they used in either a selection or a plausibility rating task. The results showed that (1) participants tended to recall rules compatible with their card selection and not with the rule as stated in the problem and (2) recall was not affected by whether or not participants performed card selection. We conclude that perspective effects in the Wason selection task do not concern how card selection is reasoned about but instead reflect the inferential text processing involved in the comprehension of the problem text. Together with earlier research that showed selection performance in nondeontic contexts to be indistinguishable from selection performance in deontic contexts (Almor \& Sloman, 1996; Sperber, Cara, \& Girotto, 1995), the present results undermine the claim that reasoning in a deontic context elicits specialized cognitive processes.
\end{abstract}

A central question regarding the nature of human reasoning is whether it operates solely on the basis of general domain-independent principles or whether reasoning is domain-specific. Many researchers believe that, in certain cases that involve social interaction, human reasoning follows a set of specialized principles (Cheng \& Holyoak, 1985; Cosmides, 1989; Gigerenzer \& Hug, 1992). Because these principles apply to situations in which a certain social convention or rule should be followed but could be violated, this form of reasoning is called deontic reasoning. Although different proponents of the view that deontic reasoning is special disagree about the form that deontic reasoning takes (Cheng \& Holyoak, 1989; Cosmides, 1989; Gigerenzer \& Hug, 1992; Oaksford \& Chater, 1994), they nevertheless share the belief that postulating a specialized type of reasoning is necessary to explain the way people reason in deontic contexts.

All of the empirical evidence supporting the claim that reasoning in deontic contexts operates on the basis of special principles comes from a single task - the Wason fourcard selection task (Wason, 1966). Although initially proposed as a demonstration of people's inability to think in a way that is compatible with formal logic (Wason,

The authors wish to acknowledge the useful comments made on earlier drafts by (in alphabetical order) Nick Chater, Gerd Gigerenzer, Steve Newstead, David Over, and Tom Ward. Correspondence should be addressed to A. Almor, Hedco Neuroscience Building, University of Southern California, Los Angeles, CA 90089-2520 (e-mail: almor@gizmo. usc.edu).
1966) and as a means of studying various factors that may help "rehabilitate" people's apparently illogical thinking (Griggs \& Cox, 1982, 1983; Wason \& Shapiro, 1971), the selection task is now often used descriptively to distinguish between domains in which reasoning complies with the prescription of formal logic and domains in which it does not (although see Oaksford \& Chater, 1994, for an argument that card selections could be viewed as rational on the grounds that they should be evaluated with respect to optimal data selection, not first-order logic). In the original Wason selection task, participants are required to decide how to test the truthfulness of an arbitrary rule of the form "if $p$, then $q$ "l like the following vowel-even number rule: "If a card has vowel on one side, then it must have an even number on the other side." They are shown four cards and are told that each card represents a single combination of $P$ and $Q$ values. Their task is to decide which cards to turn over to test the rule. Because participants can see only one side of each card (i.e., "A," "4," "B," " 7 " in the vowel-even-number problem), they have to judge, according to what is on the visible side, whether the invisible side may be useful for testing the rule. The general finding is that with many abstract problems, such as the arbitrary vowel-even-number problem, people tend to select only the $p$ card (i.e., the card with the letter "A") or both the $p$ and $q$ cards (i.e., the card with the letter " $A$ " and the card with the number " 4 ") but only seldom the $p$ and $\sim q$ cards as dictated by formal logic (i.e., the card with the letter " $A$ " and the card with the number "7"; Griggs \& Cox, 1982; Wason \& Shapiro, 1971). How- 
ever, in some domains, the $p \& \sim q$ response prescribed by formal logic is the predominant selection (Cheng \& Holyoak, 1985; Griggs \& Cox, 1983, 1993). For example, in the day-off problem used by Gigerenzer and Hug (1992), in which participants are required to test whether a rule set by a company, "if a former employee gets a day off during the week, then that employee must have worked on the weekend," is violated by employees, most participants select the $p$ and $\sim q$ cards ("an employee who gets a day off during the week," and "an employee who did not work on the weekend").

The striking difference between domains in which the "logically correct" selection, $p \& \sim q$, is effortless and intuitive, as with the day-off problem, and domains in which it is hard and seems to require conscious application of logical rules, as with the vowel-even-number problem, has been argued to be strong evidence for the uniqueness of deontic reasoning (Cheng \& Holyoak, 1985; Cosmides, 1989; Gigerenzer \& Hug, 1992). Indeed, the notion of deontic reasoning was initially based on the insight that many of the domains in which the majority of people make the selection prescribed by formal logic include some kind of social relation that should be respected yet could be violated. In these domains, it has been argued, people interpret the selection task as detecting a violation of a conventional rule, whereas in those domains in which the logically prescribed selection is rare, people interpret the task differently, as validating the truthfulness of the rule (Cheng \& Holyoak, 1985). ${ }^{2}$

Recent research, however, has shown that selection task performance compatible with the logical prescription can be elicited in a range of nondeontic domains (Almor \& Sloman, 1996; Evans, Newstead, \& Byrne, 1993; Liberman \& Klar, 1996; Sperber, Cara, \& Girotto, 1995). For example, Almor and Sloman showed that people's selection performance in domains such as containment, force dynamics, prize winning, and quality control is indistinguishable from their performance on deontic problems. Thus, the distinction between problems that lead to a high proportion of $p \& \sim q$ selections and problems that do not cannot be solely based on whether the problem is deontic or not. Rather, according to Almor and Sloman, selection task performance is determined by people's expectations for what should be on the other side of each card; the stronger the expectations people have about what is on the hidden side of a card, the more likely they are to select that card. On this view, selection in deontic problems is not a function of a specialized form of reasoning but, rather, is a function of how people represent the problem in memory. In problems that promote a high proportion of $p \& \sim q$ selections, people's memorial representation may lead them to form strong expectations about the hidden side of the $p$ and $\sim q$ cards but not about the hidden side of the $\sim p$ and $q$ cards. Whether or not this hypothesis is correct, the evidence shows that reasoning in nondeontic domains can produce the same pattern of responses as reasoning in the deontic domain. Therefore, deontic reasoning does not seem to be unique. Selection task performance showing a high proportion of $p \& \sim q$ selections does not provide evidence for a special kind of domain-specific reasoning.

A second phenomenon, based on the "reversed perspective" selection problems, has also been cited as evidence for a special form of deontic reasoning (Gigerenzer \& Hug, 1992). In a reversed perspective selection problem, the context story that provides the motivation for checking violations of a rule conflicts with the rule itself. The context and the rule make opposite suggestions about which party is bound by the rule. The general finding in these studies is that people's selection is affected to a great extent by the context story and not by the rule verbatim (Gigerenzer \& Hug, 1992). For example, using the day-off problem, Gigerenzer and Hug observed that when cued into the perspective of an employee wishing to check whether the company is not keeping its part of the deal in the day-off problem, many participants selected the "worked on the weekend" $(\sim p)$ and "did not get a day off during the week" $(q)$ cards. The most common interpretation of this finding is that, in reversed perspective problems, people are cued into a different perspective than in the nonreversed version of the same problem and are thus making a $\sim p \& q$ selection. According to Gigerenzer and Hug, a $\sim p \& q$ selection cannot be explained by any existing theory that does not treat deontic reasoning as special. Because both perspective conditions should be equally familiar to participants, theories of selection task performance that are based on the availability of related memorized experiences cannot explain the different performance in the two conditions: "No availability theory seems to have ever predicted not $P \& Q$ responses" (Gigerenzer \& Hug, 1992, p. 153). Similarly, because Cheng and Holyoak's (1985) pragmatic reasoning schema theory "has no theoretical vocabulary that applies to perspective change" (p. 153), it "should also predict a high proportion of $P \&$ not- $Q$ responses and low proportions of not-P \& $Q$ responses under both perspectives" (p. 154). Thus, the only possible explanation for $\sim p \& q$ selections, according to Gigerenzer and Hug, is that selections are determined by a cheater detection algorithm that operates from the perspective adopted by participants. By this argument, perspective effects in the selection task reinforce the view that deontic reasoning is special and, in particular, that the cheater detection algorithm is the crucial component in deontic reasoning.

Unfortunately for this argument, perspective effects have been found using nondeontic rules (Staller, Sloman, \& Ben-Zeev, 2000). Worse, Gigerenzer and Hug's (1992) argument overlooks the most fundamental characteristic of these problems-namely, that they hinge on an internal contradiction in the text of the problem. Participants in a reversed perspective experiment are confronted with a task in which a small part of the text they are given - the ruleis inconsistent with the rest of the story and, in particular, with the very motivation for that rule. For example, in the reversed perspective version of the day-off problem used by Gigerenzer and Hug, the context story suggests that this 
is an obligation problem in which the company, the party with authority, is obligated to give a day off to any employee who has worked on the weekend, whereas the rule itself is a permission rule stating that if an employee has taken a day off during the week, then that employee must have worked on the weekend. Given that people process text incrementally, integrating information into memory as they read (Gernsbacher, 1990; Johnson-Laird, 1983; Kintsch, 1988), many participants in a reversed perspective experiment, when faced with this inconsistency, may never notice the actual wording of the rule and instead might assume that they are reading the converse rule.

Indeed, people's tendency to process text in a way that is consistent with preceding context and not with the actual text has been demonstrated in many studies (e.g., Andreson, 1974; Andreson \& Paulson, 1977; Gernsbacher, 1985; Lee \& Williams, 1997; Murphy \& Shapiro, 1994; Sachs, 1967). Some of these studies have shown that people may recall an incorrect version of a text that is compatible with the rest of the narrative, especially when the narrative and the text in question are incoherent (e.g., Murphy \& Shapiro, 1994). The mechanisms behind these effects have been the topic of much research on the inferential processes that are a central part of discourse processing (e.g., McKoon \& Ratcliff, 1992; Sperber \& Wilson, 1986, 1995). This research has shown that, when faced with a text that is locally incoherent, people supplement the information explicitly mentioned in the text by employing their general knowledge to infer additional information.

According to this explanation, in a reversed perspective selection task, participants may construct a representation of the entire problem with a rule that is compatible with the rest of the problem and is different from the rule they actually read prior to card selection. If so, when participants make their card selection, they may not rely on the rule as stated in the problem but instead on the converse rule that is compatible with the rest of the text, "if $q$, then $p . "$ In that case, their $\sim p \& q$ response would in fact represent the regular $p \& \sim q$ response but for a different rule than the one stated in the problem. If this interpretation is correct, then the "perspective reversal" effects in the Wason four-card selection task could bear only on how people process text and not directly on reasoning.

Indeed, much of the reasoning on this kind of problem may consist of text processing. Polk and Newell (1995) proposed that many effects usually attributed to nonlinguistic deductive reasoning are in fact the product of the linguistic processes involved in encoding text. ${ }^{3}$ These authors argue against the common distinction between strictly verbal processes that are part of encoding a problem text and the nonverbal reasoning processes that operate once a representation is generated. Instead, they suggest that much of the reasoning involved in solving problems, such as syllogisms, is part of verbal processing because it involves repeatedly regenerating the linguistic representation until it includes a "legal conclu- sion." With respect to the selection task, Polk and Newell distinguish the verbal reasoning processes that must take place when people read the problem's text from the reasoning about card selection that calls on other "metainferential" processes beyond verbal reasoning. We agree that the Wason task does require such nonlinguistic deliberation. Our proposal is that perspective effects in the selection task reflect text processing and not the nonverbal aspects of performance.

The purpose of the present experiments was to show that it is indeed the misrepresentation of the rule that underlies reversed perspective effects in the selection task by asking participants to recall the rule after reading the problem statement in an effort to show that people encode the wrong rule. Such a result would show that an account of performance does not require hypothesizing how people reason about the rule as stated in the problem. In particular we sought to obviate the need for a special perspectivesensitive deontic reasoning.

\section{EXPERIMENT 1 Perspective Change and Rule Recall}

Experiment 1 was designed to find out which rule participants reason with in reversed perspective experiments. If, as is implicitly assumed by proponents of deontic reasoning, participants rely on the rule as stated in the problem, then perspective change findings would indeed support the notion of specialized deontic reasoning. However, if perspective change effects result from reasoning about a different rule, if participants actually select cards on the basis of a rule that is the converse of the rule stated in the problem, then perspective change effects cannot be used as an independent argument for a special form of reasoning, because they would not reflect reasoning about card selection at all.

To test whether people use a reversed version of the rule instead of the rule as stated in the problem when making selections, we conducted a reversed perspective experiment in which, after performing a regular selection task, participants were asked to recall the rule from the text. We focus on the relation between rule recall and selection responses. We expected a strong link between the rule participants recalled and their selection response such that their selection response would be more compatible with the rule they recalled than with the rule they actually read in the problem.

We used two deontic perspective change problems from Gigerenzer and Hug (1992): the day-off problem and the pension problem. Although Gigerenzer and Hug used only one version of the rule in each problem and manipulated only the perspective participants were cued into, we manipulated both the rule and the perspective such that each problem appeared in four conditions - two in which the rule and perspective were compatible, and two in which they were contradictory. We included the two remaining conditions for the sake of completeness. 


\section{Method}

Materials. Two conditions of each problem were taken from Gigerenzer and Hug (1992) and the other two conditions were generated from the original two conditions by replacing the original rules with their converses ("if $q$, then $p$ "). The text used for the two problems in all conditions appears in the Appendix.

To simplify the discussion of conditions and results we use the term company and employee to describe the two levels of the rule factor, the two levels of the perspective factor, and the selection and recall responses of interest. The two selection patterns of interest ( $p \& \sim q$ and $\sim p \& q$ ) are labeled according to whether they reflect the company's perspective (i.e., the participant marked exactly the "worked for 5 years" and "receives pension" cards in the pension problem, and the "did not work on the weekend" and "got a day off during the week" cards in the day-off problem), or the employee's perspective (i.e., the participant marked "worked for 15 years" and "does not receive pension" cards in the pension problem, and the "worked on the weekend" and "did not get a day off during the week" cards in the day-off problem). Similarly, the two relevant recall responses are labeled according to whether they convey the perspective of the company or employee.

Participants. One hundred fifteen Brown University undergraduates participating in introductory psychology and cognitive science classes volunteered to participate in this experiment.

Procedure. Questionnaires were distributed and completed in the classroom. Each questionnaire consisted of a cover page with general instructions, 2 pages with one version from each problem, and a final page in which participants were asked to recall the rules from the preceding problems. The participants were instructed never to turn back to previous pages. The participants were closely monitored to ensure that they followed the instructions. The order of questions was balanced across questionnaires. Versions of the two problems were also balanced across questionnaires so that each version of each problem appeared with each version of the other problem on an equal number of questionnaires. The order of the four cards was changed between problems in the same questionnaire so that the participants could not use card order as a cue. Following the questionnaire, the participants indicated if they were familiar with the task.

Selection task responses were categorized according to whether they were consistent with the company's perspective or the employee's perspective. To be considered consistent with a perspective of one party (company or employee), a selection response had to consist of only the two cards that may indicate that the other party violated its commitment. Selection responses not consisting of exactly the two cards representing the perspective of the company or employee were recorded as "neither."

Recall responses were categorized according to the following criterion: If the recalled rule unambiguously expressed a commitment of one of the participating parties (company or employee), it was categorized as compatible with the other party's perspective. For example, the recalled rule "if worked on the weekend, then will get a weekday off" was categorized as an employee recall because it expresses the company's commitment to the employee. If the participant failed to recall the rule or if the recalled rule did not unambiguously express a commitment of one of the parties (e.g., "got a day off during the week and worked on the weekend"), then recall was categorized as "neither." The coder of recalled rules was blind to the recall condition.

\section{Results and Discussion}

Five participants indicated that they were familiar with the task. The percentages of employee and company selection and recall responses from the 110 remaining participants are shown in Table 1 . We start by analyzing se-
Table 1

Percentage of Selection and Recall Responses in Experiment 1

\begin{tabular}{cccccc}
\hline & \multicolumn{2}{c}{ Company Response } & & \multicolumn{2}{c}{ Employee Response } \\
\cline { 2 - 3 } Condition & Selection & Recall & & Selection & Recall \\
Company Rule & \multicolumn{2}{c}{ Pension Problem } & & \\
$\quad$ Company perspective & 59 & 62 & 0 & 17 \\
$\quad$ Employee perspective & 10 & 38 & 52 & 48 \\
Employee Rule & & & & \\
$\quad$ Company perspective & 36 & 11 & 16 & 68 \\
Employee perspective & 7 & 0 & 52 & 76
\end{tabular}

$\begin{array}{lrrrr} & \text { Day-Off Problem } & & \\ \text { Company Rule } & & & & \\ \text { Company perspective } & 52 & 83 & 10 & 3 \\ \text { Employee perspective } & 29 & 55 & 21 & 24 \\ \text { Employee Rule } & & & & \\ \text { Company perspective } & 42 & 18 & 12 & 54 \\ \text { Employee perspective } & 0 & 0 & 44 & 89\end{array}$

Total Both Problems

Company Rule

$\begin{array}{lllll}\text { Company perspective } & 56 & 73 & 5 & 10\end{array}$

$\begin{array}{lllll}\text { Employee perspective } & 20 & 46 & 37 & 36\end{array}$

Employee Rule

$\begin{array}{lllll}\text { Company perspective } & 39 & 15 & 14 & 61\end{array}$

$\begin{array}{lrrrr}\text { Employee perspective } & 4 & 0 & 48 & 81\end{array}$

Note-A company response refers to a selection or rule compatible with the company's perspective. An employee response refers to a selection or rule compatible with the employee's perspective.

lection and recall responses separately and then consider them together.

Selection task. The pattern of selections matched that of Gigerenzer and Hug (1992) in the subset of our conditions that they used. However, we did observe lower proportions of perspective compatible responses in all conditions. This may be because our participants responded to only two selection problems each, thus yielding a smaller transfer effect (Cheng \& Holyoak, 1985). Gigerenzer and Hug's participants had to solve 18 selection problems each. We also found a reversed perspective effect in the two conditions that they did not test. Table 1 shows that the proportion of employee selection responses to company selection responses was always higher in the employee perspective conditions than in the matching company perspective conditions. To test which factors affected selection responses, we carried out a log-linear analysis on these responses starting with the maximal model: problem (day off vs. pension) $\times$ rule (company vs. employee) $\times$ perspective (company vs. employee) $\times$ selection-task response (company vs. employee vs. neither). We used the BMDP statistics package, which systematically removes components from the model that is fit to the data, so as to see which terms in the model are important for the model's fit. The program performs an exhaustive test of all the possible hierarchical models and, on the basis of comparing all these models, lists the terms that are important for the model fit together with a likelihood ratio (LR) chi-square statistic that expresses 
the estimated contribution of these terms to the model's fit. The only terms that are of potential interest here are the interaction terms that included the selection task response factor and that were crucial for the model's fit. The only terms that met these criteria in this experiment were the term expressing the interaction between rule and selection [LR $\left.\chi^{2}(2)=9.21, p<.01\right]$ and the term expressing the interaction between perspective and selection [LR $\left.\chi^{2}(2)=52.33, p<.0001\right]$. No other two-way or higher order interaction term was necessary for the model's fit. We conclude that both the perspective and the rule affected selection responses. This suggests that the participants used both the text and the stated rule to determine their card selections.

Recall task. Table 1 shows that, as in the selection task, the proportion of employee recall responses to company recall responses was always higher in the employee perspective conditions than in the matching company perspective conditions. To test which factors affected recall responses, we carried out a log-linear analysis on these data: problem (day off vs. pension) $\times$ rule (company vs. employee) $\times$ perspective (company vs. employee) $\times$ recall (company vs. employee vs. neither). As in the selection task analysis, the only two interaction terms that included the recall factor and that were shown to be crucial for the model's fit were the interaction of rule and recall [LR $\left.\chi^{2}(2)=92.76, p<.0001\right]$ and perspective and recall [LR $\left.\chi^{2}(2)=19.22, p<.0001\right]$.

Relation between selection and recall responses. To analyze the relation between the two kinds of responses, we combined the responses from the pension and day-off problems (see the bottom part of Table 1). Using these combined results from the two problems, we conducted a chi-square test of the interaction between recall kind (company, employee, or neither) and selection task response (company, employee, or neither). The test indicated a highly significant dependence $\left[\chi^{2}(4)=29.34, p<.001\right]$, indicating that selection task responses were related to recall responses.

To get a better estimate of the nature of this dependence between the two kinds of responses, we calculated the conditional probabilities of a given selection task response given the recall rcsponse. These probabilities, listed in Table 2, show that the participants were more likely to respond to the selection task by choosing the cards consistent with the rule they recalled $[M(.40, .49)=.45]$ than with the rule as stated in the problem $[M(.40, .11)=.26]$.

In summary, the results of Experiment 1 point to the important role that memory may be playing in the re- versed perspective selection task. The same factors that underlie selection responses, the rule and the perspective, also affect rule recall. Furthermore, the recalled rule is a stronger predictor of selection responses than the rule as it appeared in the problem. Overall, these results suggest that selection reasoning is tightly linked to the representation of the rule. However, these results do not speak to the issue of whether it is the memorial representation that drives selection responses or whether reasoning about card selection shapes the representation and thus induces a particular pattern of recall responses.

\section{EXPERIMENT 2 Rule Recall With and Without Selection}

Our argument is that reversed perspective effects are a consequence of the way participants represent the rule. This means that the representations that are responsible for the reversed perspective effect in the selection task have been formed prior to actual card selection. Thus, we predict that people should exhibit a reversed perspective effect in recall even without performing the selection task. This would further indicate that reversed perspective is not a consequence of reasoning for card selection but, rather, is a consequence of the representation of the rule in the context of the problem. To test this prediction, we substituted a plausibility rating task for the selection task using the problems of Experiment 1. Although we have no a priori reason to suspect that the plausibility rating task would be sensitive to the same factors that affect performance in the selection task, we believe that subsequent recall would. To compare the effects of the two tasks - selection and plausibility rating-on recall, we had participants perform the two tasks, one on each problem, and then asked them to recall the two rules.

\footnotetext{
Method

Materials. The same materials were used as in Experiment 1.

Participants. Forty-four University of Southern California and 77 Brown University undergraduate students taking introductory psychology and cognitive science classes volunteered to participate in this study. The Brown participants were induced by a lottery wherein one participant drawn at random was awarded a $\$ 20$ cash prize. Questionnaires were distributed and completed in the classroom, and the participants were closely monitored to ensure that they followed the instructions and did not turn back to previous pages.

Procedure. Instead of solving two selection problems as in Experiment 1 , the participants performed the selection task with one problem and were only asked to indicate how reasonable the story sounded to them on a scale of $1-7$, where 1 was completely unreasonable and 7 was perfectly reasonable, for the other problem. The
}

Table 2

Summary of the Conditional Probabilities in Experiment 1 , $p$ (Selection Task Response $\mid$ Recall Response)

Selection Task Response

\begin{tabular}{lccc} 
Recall Response & Compatible with the Rule $(p \& \sim q)$ & Incompatible with the Rule $(\sim p \& q)$ \\
\hline Correct $(p \& \sim q)$ & .40 & .17 \\
Inverse $(\sim p \& q)$ & .11 & .49
\end{tabular}


participants marked their judgment on a scale showing all the numbers from 1 to 7 . The order of presentation of the two problems, as well as the matching of problem, task, and condition, was counterbalanced across questionnaires.

As in Experiment 1, questionnaires were distributed in the classroom. Each questionnaire consisted of a cover page with general instructions, 2 pages with one version from each problem, and a final page in which the participants were asked to recall the rules from the preceding problems.

\section{Results and Discussion}

The data from 1 participant were removed because this participant indicated familiarity with the task. The data from the remaining 120 participants are shown in Table $3 \mathrm{~A}$ (selection responses and recall of selection rules) and Table 3B (plausibility rating and recall of plausibility rating rules). We start by analyzing the selection responses and plausibility ratings separately and then consider their interaction with the recall data.

Selection task. A log-linear analysis on selection responses starting, as before, with the maximal model-problem (day off vs. pension) $\times$ rule (company vs. employee) $\times$ perspective (company vs. employee) $\times$ selection-task response (company vs. employee vs. neither)-implicated, as in Experiment 1, a significant interaction between rule and selection [LR $\left.\chi^{2}(2)=10.63, p<.005\right]$ and between perspective and selection [LR $\chi^{2}(2)=$ $28.32, p<.0001]$. However, in Experiment 2, there was also an interaction between problem, perspective, and selection [LR $\chi^{2}(2)=8.13, p<.05$ ], caused by the lack of any employee-compatible selections in the employee rulecompany perspective version of the pension problem. In any case, the pattern of selection task performance in Experiment 2 replicated that of Experiment 1 and of Gigerenzer and Hug (1992).

Table 3A

Percentage of Selection and Recall Responses for Selection Rules in Experiment 2

\begin{tabular}{|c|c|c|c|c|}
\hline \multirow[b]{2}{*}{ Condition } & \multicolumn{2}{|c|}{ Company Response } & \multicolumn{2}{|c|}{ Employee Response } \\
\hline & Selection & Recall & Selection & Recall \\
\hline \multicolumn{5}{|c|}{ Pension Problem } \\
\hline \multicolumn{5}{|l|}{ Company Rule } \\
\hline Company perspective & 29 & 79 & 0 & 14 \\
\hline Employee perspective & 20 & 40 & 40 & 30 \\
\hline \multicolumn{5}{|l|}{ Employee Rule } \\
\hline Company perspective & 40 & 20 & 0 & 60 \\
\hline Employee perspective & 6 & 0 & 56 & 100 \\
\hline \multicolumn{5}{|c|}{ Day-Off Problem } \\
\hline \multicolumn{5}{|l|}{ Company Rule } \\
\hline Company perspective & 75 & 63 & 0 & 13 \\
\hline Employee perspective & 26 & 61 & 17 & 30 \\
\hline \multicolumn{5}{|l|}{ Employee Rule } \\
\hline Company perspective & 38 & 23 & 23 & 54 \\
\hline Employee perspective & 0 & 0 & 44 & 83 \\
\hline \multicolumn{5}{|c|}{ Total Both Problems } \\
\hline \multicolumn{5}{|l|}{ Company Rule } \\
\hline Company perspective & 53 & 70 & 0 & 13 \\
\hline Employee perspective & 24 & 55 & 24 & 30 \\
\hline \multicolumn{5}{|l|}{ Employee Rule } \\
\hline Company perspective & 39 & 22 & 13 & 57 \\
\hline Employee perspective & 3 & 0 & 50 & 91 \\
\hline
\end{tabular}

Table 3B

Mean Plausibility Ratings and Recall Percentages for Plausibility Rules in Experiment 2

\begin{tabular}{lccc}
\hline & & \multicolumn{2}{c}{ Recall } \\
\cline { 3 - 4 } Condition & Plausibility Rating & Company & Employee \\
\hline & Pension Problem & & \\
Company Rule & & & \\
$\quad$ Company perspective & 3.69 & 69 & 13 \\
$\quad$ Employee perspective & 4.63 & 58 & 21 \\
Employee Rule & & & \\
$\quad$ Company perspective & 3.73 & 27 & 40 \\
Employee perspective & 4.55 & 0 & 80 \\
& Day-Off Problem & & \\
Company Rule & & & \\
Company perspective & 3.36 & 50 & 14 \\
$\quad$ Employee perspective & 3.85 & 46 & 38 \\
Employee Rule & & & \\
Company perspective & 3.75 & 25 & 67 \\
Employee perspective & 5.27 & 0 & 100 \\
& Total Both Problems & & \\
Company Rule & & & \\
Company perspective & 3.53 & 60 & 13 \\
$\quad$ Employee perspective & 4.31 & 53 & 28 \\
Employee Rule & & & \\
Company perspective & 3.74 & 26 & 52 \\
Employee perspective & 4.81 & 0 & 87 \\
\hline
\end{tabular}

Plausibility rating task. Although there was an "employee advantage" trend in the plausibility ratings, such that conditions with an employee perspective or rule were rated as more plausible than conditions with a company perspective or rule, a log-linear analysis on the plausibility ratings, starting with the maximal model--problem (day off vs. pension) $\times$ rule (company vs. employee) $\times$ perspective (company vs. employee) $\times$ rating $(1,2,3$, $4,5,6,7$, or no response)-revealed no significant interaction that included the rating. Importantly, the lack of interaction between rule and plausibility rating and between perspective and plausibility rating shows that performance on the plausibility rating task was affected by a different set of factors than was performance on the selection task.

Recall task. We carried out a log-linear analysis on the recall response data to see whether the two tasks affected recall patterns differently and whether the same recall pattern as in Experiment 1 was obtained. The analysis, starting with the maximal model - task (selection vs. rating) $\times$ problem (day off vs. pension) $\times$ rule (company vs. employee) $\times$ perspective (company vs. employee) $X$ recall (company vs. employee vs. neither) - as the baseline, showed that the only significant interaction terms that included the recall factor were, as before, the interaction between rule and recall [LR $\chi^{2}(2)=85.89, p<$ $.0001]$ and the interaction between perspective and recall [LR $\left.\chi^{2}(2)=21.80, p<.0001\right]$.

Selection and recall tasks. As in Experiment 1, we analyzed the relation between the two kinds of responses by combining the responses across the pension and dayoff problems (the bottom part of Table 3A). A chi-square test showed that the relation between recall kind (com- 
Table 4

Summary of the Conditional Probabilities in Experiment 2 , $p$ (Selection Task Response | Recall Response)

\begin{tabular}{lcc} 
& \multicolumn{2}{c}{ Selection Task Response } \\
\cline { 2 - 3 } Recall Response & Compatible with the Rule $(p \& \sim q)$ & Incompatible with the Rule $(\sim p \& q)$ \\
\hline Correct $(p \& \sim q)$ & .43 & .07 \\
Inverse $(\sim p \& q)$ & .05 & .37 \\
\hline
\end{tabular}

pany, employee, or neither) and selection task response (company, employee, or neither) was highly significant $\left[\chi^{2}(4)=30.66, p<.0001\right]$. Again, selection task responses were linked to the recall responses.

As before, we calculated the conditional probabilities of a given selection task response given the recall response. These conditional probabilities, appearing in Table 4, again show that the participants were more likely to respond to the selection task by choosing the cards consistent with the rule they recalled $[M(.43, .37)=.40]$ than with the rule as stated in the problem $[M(.43, .05)=.24]$.

The results of Experiment 2 replicated those of Experiment 1: Recall and selection responses were influenced by the same factors, and the recalled rule was a better predictor of selection responses than the actual rule in the problem. Moreover, rule recall was unaffected by whether the participants performed a selection task or a plausibility rating task, a task that is influenced by a different set of factors. Thus, the representation that is strongly linked with selection responses is not generated as consequence of performing the selection task but is generated independently, probably as a direct consequence of reading the rule in the context of the problem text.

\section{EXPERIMENT 3 Rule Recall Without Selection}

Experiment 2 showed that recall patterns are insensitive to the task performed in the context of the rule. Nevertheless, recall took place after the participants had done one selection task. The possibility remains that this selection task was sufficient to cue the participants into a "reasoning mode" that affected recall results even for the plausibility rating problem. To see whether the recall results obtained in Experiments 1 and 2 were truly independent of the card selection task, we conducted Experiment 3 in which participants were asked to rate the plausibility of the two problems and did not perform any card selection. A recall pattern in this experiment similar to the one observed in Experiments 1 and 2 could not be attributed to card selection reasoning.

\section{Method}

Materials. The same materials were used as in Experiments 1 and 2.

Participants. Ninety-eight different University of Southern California undergraduate students participating in introductory psychology and linguistics classes volunteered to participate in this experiment. Questionnaires were distributed and completed in the classroom, and the participants were closely monitored to ensure that they followed the instructions.

Procedure. The same design and procedure were used as in Experiment 2, except that, instead of performing one selection task and one plausibility rating task, the participants had to rate the plausibility of the two problem stories on a scale of 1-7.

\section{Results and Discussion}

Table 5 shows the mean plausibility rating for each condition as well as the percentages of company and employee recalls in each condition.

Plausibility rating task. A log-linear analysis on the plausibility ratings, starting with the maximal modelproblem (day off vs. pension) $\times$ rule (company vs. employee) $\times$ perspective (company vs. employee) $\times$ rating $(1,2,3,4,5,6,7$, or no response) - found two interaction terms necessary for the model's fit. First, an interaction between perspective and rating $\left[\operatorname{LR} \chi^{2}(6)=18.37, p<\right.$ $.01]$, such that plausibility ratings from the employee perspective were higher than those from the company perspective. Second, an interaction between rule, perspective, and rating [LR $\left.\chi^{2}(6)=19.64, p<.005\right]$, such that the employee perspective advantage in plausibility rating was larger in the employee rule conditions than in

Table 5

Plausibility Ratings and Recall Percentages in Experiment 3

\begin{tabular}{lccc}
\hline & & \multicolumn{2}{c}{ Recall } \\
\cline { 3 - 4 } Condition & Plausibility Rating & Company & Employee \\
\hline & Pension Problem & & \\
Company Rule & & & \\
$\quad$ Company perspective & 4.41 & 74 & 7 \\
Employee perspective & 4.41 & 45 & 32 \\
Employee Rule & & & \\
Company perspective & 3.42 & 29 & 54 \\
Employee perspective & 5.00 & 0 & 76 \\
& Day-Off Problem & & \\
Company Rule & & & \\
Company perspective & 3.89 & 50 & 7 \\
Employee perspective & 4.16 & 56 & 32 \\
Employee Rule & & & \\
Company perspective & 3.27 & 18 & 68 \\
Employee perspective & 5.26 & 0 & 87 \\
& Total Both Problems & & \\
Company Rule & & & \\
Company perspective & 4.15 & 62 & 7 \\
Employee perspective & 4.29 & 51 & 32 \\
Employee Rule & & & \\
Company perspective & 3.35 & 24 & 62 \\
Employee perspective & 5.13 & 0 & 81 \\
\hline
\end{tabular}


the company rule conditions. No other interaction term was significant. Thus, in Experiment 3, plausibility ratings were affected by how "employee oriented" each problem was - whether the perspective, and, to a lesser extent, the rule, reflected the employee's point of view. Stronger employee orientation yielded higher plausibility scores. Although a similar trend was also observed in Experiment 2, the effect in Experiment 2 was not reliable, possibly due to the larger number of plausibility rating responses in Experiment 3 (each participant provided two plausibility responses in Experiment 3 but only one plausibility response in Experiment 2). Because performance in the plausibility rating task itself was never thought to provide any useful information for the present purpose, we do not discuss this issue further except to note that the "employee bias" in this task shows that performance in this task is affected by different factors than performance in the selection task.

Recall task. As in Experiments 1 and 2, the proportions of employee recall responses to company recall responses in Table 5 show that recall was affected by the rule and perspective. An analysis of the recall response data - problem (day off vs. pension) $\times$ rule (company vs. employee) $\times$ perspective (company vs. employee) $\times$ recall (company vs. employee vs. neither) - found three interaction terms that included the recall factor and were significant for the model's fit: an interaction between rule and recall [LR $\left.\chi^{2}(2)=68.61, p<.0001\right]$, an interaction between perspective and recall [LR $\chi^{2}(2)=$ $14.71, p<.001]$, and, finally, a three-way interaction between rule, perspective, and recall $\left[\operatorname{LR} \chi^{2}(3)=12.03\right.$, $p<.01]$. Experiment 3 clearly replicated the interactions between rule and recall and between perspective and recall observed in Experiments 1 and 2. The three-way interaction was not reliable in Experiments 1 and 2, although a similar trend was observed.

In summary, although the participants in Experiment 3 did not perform the selection task at all but instead rated the plausibility of the problems, recall responses showed a similar pattern to that in Experiments 1 and 2. Together with the lack of any task effect on recall responses in Experiment 2 , this finding shows that recall responses were not induced by the selection task. Thus, our interpretation of the parallelism in recall and selection task performance is that both tasks depend on the same mental representation of the conditional rule.

\section{GENERAL DISCUSSION}

In three experiments, we have shown that people are likely to retrieve a rule that is the converse of the one presented to them if the converse is more compatible with the problem context than the stated rule is. We have also shown that card selections on the Wason four-card selection task are more compatible with this recalled rule than with the stated rule. Finally, we have shown that this pattern of recall emerges whether or not participants engage in the selection task; the same results were ob- served after participants performed a plausibility rating of the problem. Therefore, the selection task is not responsible for rule recall. Presumably, whatever is responsible for converse rule recall is also responsible for selection reversals.

These data are easily explained by the hypothesis that selection task performance is a product of two distinct processing stages that operate in sequence (e.g., Evans, 1996; Polk \& Newell, 1995). The first is the construction of a representation of the problem text, a representation that is encoded into memory. This stage involves all the processes that are part of regular text interpretationmost importantly, the inferential processes that are required for establishing local coherence (e.g., McKoon \& Ratcliff, 1992; Sperber \& Wilson, 1986, 1995). The second stage is the selection of cards, controlled by the representation in memory. The research reported here does not bear on the nature of the processes that operate at this second stage (see Evans, 1996, for discussion of this issue, but cf. Evans, 1998, Roberts, 1998a, 1998b). Rather, our recall results show that perspective manipulations have an effect in the first stage. As such, our results are compatible with much research on discourse processing that shows that when local coherence cannot be easily established, an inference occurs to resolve the discrepancy (e.g., McKoon \& Ratcliff, 1992; Sperber \& Wilson, $1986,1995)$. Participants reading a rule that is incompatible with the preceding context (e.g., a rule expressing an obligation in a context concerning permission) attempt to maintain local coherence by drawing an inference that results in the misrepresentation of the rule. Actual card selection does not modulate this inferential process; the perspective effect on recall is present even when card selection is not performed.

Deontic reasoning theorists clearly have a ready explanation for our results. They could argue that specialized processes for deontic domains are involved in constructing the converse rule using the problem context (Holyoak \& Cheng, 1995). But calling such processes "deontic"-indeed, making them domain-specific in any sense - is not only ad hoc but unnecessary. Clearly, some knowledge and processing capability must be involved in constructing interpretations of a text. Giving special status to the deontic portion of that knowledge and capacity does not help to explain selection task performance except to say that it depends on how text is integrated into the representation of a problem. Several theorists have proposed (Almor \& Sloman, 1996; Evans et al., 1993; Liberman \& Klar, 1996; Sperber et al., 1995) that card selection itself is a domain-independent process that operates on the basis of people's expectations: The higher the expectation people have for what should be on the hidden side of a card, the more likely they are to select that card. Staller et al. (2000) argue that expectations can be controlled by the availability of counterexamples. Obviously, people have different amounts and organizations of knowledge about a domain, and reasoning may well depend on the content and structure of that knowl- 
edge. Our central claim is that neither "logical selection" nor perspective effects in the selection task provide evidence for domain-specific reasoning processes. Theories of text and discourse processing agree that different knowledge bases breed different expectations in all domains (Gernsbacher, 1990; Kintsch, 1988, 1993; McKoon \& Ratcliff, 1992; Sperber \& Wilson, 1986, 1995).

Although all proponents of deontic reasoning share the assumption that a $p \& \sim q$ selection is contingent on people's ability to represent the task as detecting a social violation, they disagree on the nature of the underlying mechanism. Originally, Cheng and Holyoak (1985) proposed that this deontic knowledge is represented as a pragmatic reasoning schema consisting of a small set of production rules and that this schema is the product of extensive experience with deontic problems. Although the present findings and our previous findings of high proportions of $p \& \sim q$ responses in nondeontic domains (Almor \& Sloman, 1996) can be reconciled with Cheng and Holyoak's theory by expanding the inventory of reasoning schema to include other domains and arguing that they apply at the text processing stage, such an approach would be unparsimonious. People know much more about each domain than the few production rules that constitute Cheng and Holyoak's reasoning schema. For example, in permission situations, people not only know the relations between preconditions and actions, but they also know that the relative power of the two parties matters and that their age matters (Kirby, 1994). Furthermore, this richer kind of knowledge is precisely the kind of knowledge that has been found to guide the inferences that help to form text representations (e.g., Murphy \& Shapiro, 1994). Thus, the claim that pragmatic reasoning schema operate at the text processing stage is incomplete; representations of text involve much more knowledge than pragmatic reasoning schema maintain. The claim that these schema operate at the card selection stage is unnecessary because the effect of knowledge can be found in the text processing stage. Card selection is a domainindependent process that takes advantage of the expectations afforded by the representation of the problem.

Cosmides (1989) suggested that deontic reasoning is part of the human genetic endowment consisting of algorithms that are hard-wired to detect violation of social contracts. Cosmides's argument has not withstood analysis (especially that of Cheng \& Holyoak, 1989). Cummins (1996a, 1996b, 1996c) has argued instead that deontic reasoning is not the product of an adaptation to detect violations of social contracts but instead reflects an earlier adaptation in primate evolution for negotiating the risks and benefits associated with certain behaviors in the context of dominance hierarchies. Unfortunately, all the empirical evidence underlying Cummins's argument, specifically the different performance of 3and 4-year olds with deontic and nondeontic selection problems, could be easily attributed to the different experience children typically have with the two kinds of problems (Chater \& Oaksford, 1996). Gigerenzer and Hug
(1992), elaborating on Cosmides's ideas, argued that the violation detection algorithms are specially geared to detect cheaters and cannot be applied in cases that do not allow cheating. This argument that deontic reasoning is innate has been undermined by the experiments in this study and in that of Staller et al. (2000). Current evidence does not call for a special cheater detection or social contract violation mechanism for text processing that is different from the mechanisms involved in processing text in other domains. In all these cases, knowledge and perspective affect representation.

Before stipulating highly specialized, genetically specified mechanisms of reasoning, the contribution of ontogeny must be ruled out. For example, given the extremely long maturation period in humans and especially the strong dependence of children on their parents during the first years of life, people may acquire much of their knowledge about their duties and obligations in social situations early in life as they negotiate access to resources with their parents, siblings, and others with whom they must share. Indeed, the importance of resource distribution in explaining familial relationships is widely acknowledged in evolutionary psychology (e.g., Pinker, 1997). The fact that some aspects of social behavior are already prevalent at 3 years of age (Cummins, 1996b) may thus be due to the importance of this kind of social interaction to the child and not to innately specified knowledge, except for a general instinct to gain access to resources. If social knowledge is the product of the development of general skills involved in negotiating resource distribution, then selecting for a redundant specialized social knowledge would confer no evolutionary advantage.

Reasoning in the deontic domain is "special" only in the sense that special logics are required for expressing certain deontic relations. For example, the deontic conditional does not have the same truth conditions as the material conditional of propositional logic. The statement "If you do $X$, then you may have $Y$ " is not falsified by the observation that you do $X$ but do not get $Y$. You may not want $Y$. This logical specialization of the deontic domain obtains whether or not an evolutionary specialization does-a fact that seems to undermine the evolutionary claim. In particular, this logic specialization relies on complex knowledge regarding social relations and utilities that would not be available to the specialized modules assumed by current evolutionary theories (see Over, 1999, and Staller et al., 2000, for discussion).

Conclusions about the specialization or innateness of reasoning cannot be drawn from a single task that is difficult to understand for both experimental participants and psychological theorists (Sperber et al., 1995). The research we report here shows that the selection task can be reduced to two conventional processing stages: a stage of interpretation and a stage of deliberative reasoning. The fact that the selection task is conventional in this sense suggests that the formidable amount of research that has gone into it may generalize to other tasks. 


\section{REFERENCES}

Almor, A., \& Sloman, S. A. (1996). Is deontic reasoning special? Psychological Review, 103, 374-380.

ANDRESON, J. R. (1974). Verbatim and propositional representation of sentences in immediate and long term memory. Journal of Verbal Learning \& Verbal Behavior, 13, 149-162.

AndReson, J. R., \& PAUlson, R. (1977). Representation and retention of verbatim information. Journal of Verbal Learning \& Verbal Behavior, 16, 439-451.

Chater, N., \& OAKsford, M. (1996). Deontic reasoning, modules and innateness: A second look. Mind \& Language, 11, 191-202.

Cheng, P. W., \& Holyoak, K. J. (1985). Pragmatic reasoning schemas. Cognitive Psychology, 17, 391-416.

Cheng, P. W., \& Holyoak, K. J. (1989). On the natural selection of reasoning theories. Cognition, 33, 285-313.

Cosmides, L. (1989). The logic of social exchange: Has natural selection shaped how humans reason? Studies with the Wason selection task. Cognition, 31, 187-276.

Cummins, D. D. (1996a). Dominance hierarchies and the evolution of human reasoning. Minds \& Machines, 6, 463-480.

Cummins, D. D. (1996b). Evidence of deontic reasoning in 3- and 4year-old children. Memory \& Cognition, 24, 823-829.

Cummins, D. D. (1996c). Evidence for the innateness of deontic reasoning. Mind \& Language, 11, 160-190.

Evans, J. S. B. T. (1996). Deciding before you think: Relevance and reasoning in the selection task. British Journal of Psychology, 87, 223-240.

Evans, J. S. B. T. (1998). Inspection times, relevance, and reasoning: A reply to Roberts. Quarterly Journal of Experimental Psychology, 51A, $811-814$.

Evans, J. S. B. T., Newstead, S. E., \& Byrne, R. M. J. (1993). Human reasoning: The psychology of deduction. Hillsdale, NJ: Erlbaum.

Gernsbacher, M. A. (1985). Surface information loss in comprehension. Cognitive Psvchologv, 17, 324-363.

GeRnSBACHER, M. A. (1990). Language comprehension as structure building. Hillsdale, NJ: Erlbaum.

GigerenZer, G., \& Hug, K. (1992). Domain-specific reasoning: Social contracts, cheating, and perspective change. Cognition, 43, 127-171.

Griggs, R. A., \& Cox, J. R. (1982). The elusive thematic-materials effect in Wason's selection task. British Journal of Psychology, 73, 407-420.

GrigGs, R. A., \& Cox, J. R. (1983). The effects of problem content and negation on Wason's selection task. Quarterly Journal of Experimental Psychology, 35A, 519-533.

Griggs, R. A., \& Cox, J. R. (1993). Permission schemas and the selection task. Quarterly Journal of Experimental Psychology, 46A, 637-651.

Holyoak, K. J. \& ChENG, P. W. (1995). Pragmatic reasoning from multiple points of view: A response. Thinking \& Reasoning, 1, 373-388.

JoHNSON-LAIRD, P. N. ( 1983). Mental models: Towards a cognitive science of language, inference, and consciousness (Vol. 6). Cambridge, MA: Harvard University Press.

KINTSCH, W. (1988). The role of knowledge in discourse comprehension: A construction-integration model. Psychological Review, 95, 163-182.

KINTSCH, W. (1993). Information accretion and reduction in text processing: Inferences. Discourse Processes, 16, 193-202.

KIRBY, K. N. (1994). Probabilities and utilities of fictional outcomes in Wason's four-card selection task. Cognition, 51, 1-28.

LEE, M.-W., \& WiLliams, J. N. (1997). Why is short-term sentence re- call verbatim? An evaluation of the role of lexical priming. Memory \& Cognition, 25, 156-172.

Liberman, N., \& Klar, Y. (1996). Hypothesis testing in Wason's selection task: Social exchange cheating detection or task understanding. Cognition, 58, 127-156.

McKoon, G., \& RATCLIFF, R. (1992). Inference during reading. Psychological Review, 99, 440-466.

MURPHy, G. L., \& ShapiRo, A. M. (1994). Forgetting of verbatim information in discourse. Memory \& Cognition, 22, 85-94.

OAKSFORD, M., \& CHATER, N. (1994). A rational analysis of the selection task as optimal data selection. Psychological Review, 101, 608-631.

OvEr, D. E. (1999). Logic and decision making. In S. B. Cooper \& J. K Truss (Eds.), Models and computability: Invited papers from the European Meeting of the Association for Symbolic Logic, Leeds, July 1997 (pp. 313-338). Cambridge: Cambridge University Press.

Pinker, S. (1997). How the mind works (1st ed.). New York: Norton.

Polk, T. A., \& Newell, A. (1995). Deduction as verbal reasoning. Psychological Review, 102, 533-566.

RoBerTS, M. J. (1998a). How should relevance be defined? What does inspection time measure? A reply to Evans. Quarterly Journal of Experimental Psychology, 51A, 815-817.

RoBerTs, M. J. (1998b). Inspection times and the selection task: Are they relevant? Quarterly Journal of Experimental Psychology, 51A, $781-810$.

SACHS, J. S. (1967). Recognition memory for syntactic and semantic aspects of connected discourse. Perception \& Psychophysics, 2(9), $437-442$

Sperber, D., Cara, F., \& Girotto, V. (1995). Relevance theory explains the selection task. Cognition, 57, 31-95.

Sperber, D., \& Wilson, D. (1986). Relevance: Communication and cognition (1 st ed.). Cambridge, MA: Harvard University Press.

Sperber, D., \& Wilson, D. (1995). Relevance: Communication and Cognition (2nd ed.). Oxford: Blackwell.

Staller, A., Sloman, S. A., \& Ben-Zeev, T. (2000). Perspective effects in nondeontic versions of the Wason selection task. Memory $\&$ Cognition, 28, 396-405.

WASON, P. C. (1966). Reasoning. In B. M. Foss (Ed.), New horizons in psychology (pp. 135-151). Harmondsworth, U.K.: Penguin.

WASON, P. C., \& Shapiro, D. (1971). Natural and contrived experience in a reasoning problem. Quarterly Journal of Experimental Psychology, 23, 63-71.

\section{NOTES}

1. We follow conventional notation in specifying variables names in large caps (e.g., $P$ and $Q$ ) and variable values in small caps (e.g.. $p, \sim p$, $q, \sim q)$.

2. Oaksford and Chater (1994) further claim that deontic and nondeontic selection tasks have different correct solutions. By their account, the common $p$ and $p \& q$ responses in nondeontic selection problems are in fact the rational choices. However, once informed about the "logical analysis" of the selection task, almost everyone agrees that the $p \& \sim q$ solution is the correct one. We find it hard to imagine that many informed people would accept the validity of the $p$ and $p \& q$ responses; for example, our sense is that only a minority of reasoning researchers do.

3. We would like to thank Tom Ward for drawing our attention to the potential connections between this work and our own. 


\section{APPENDIX \\ The Day-Off and Pension Problems in All Perspectives With Company Rule as Used in Experiments 1-3 (The Employee Rule Appears in Italics)}

\section{Pension Problem}

\section{Company Perspective}

In order to encourage employees to stay with the firm, a certain firm has established the following rule: "If a previous employee gets a pension from the firm, then that person must have worked for the firm for at least ten years." "If a previous employee had worked for the firm for at least ten years, then that person will get a pension from the firm."

However, the management has heard some rumors that the rule has been violated by employees in the past. To verify whether the rule has been violated, the management looks into the cases of four former employees of the firm.

\section{Employee Perspective}

Joe has been working for a firm for over ten years, and is now interested in quitting since he is no longer enjoying his job. In order to encourage employees to stay, the firm has established the following rule: "If a previous employee gets a pension from the firm, then that person must have worked for the firm for at least ten years." "If a previous employee had worked for the firm for at least ten years, then that person will get a pension from the firm."

Joe is concerned since he heard many rumors that the firm has violated the rule before. To verify whether the rule has been violated, Joe decides to talk to four former employees of the firm.

\section{Day-Off Problem}

\section{Company Perspective}

A factory is interested in motivating its employees to work on weekends to make effective use of the machines and to allow more flexibility in manufacturing schedules. The management has set the rule: "If an employee gets a day off during the week, then that person must have worked on the weekend." "If an employee works on the weekend, then that person gets a day off during the week."

The management has heard many rumors that employees have violated the rule in the past. To verify whether the rule has been violated the management looks at the files of four workers.

\section{Employee Perspective}

Robert's company is interested in motivating its employees to work on weekends to make effective use of the machines and to allow more flexibility in manufacturing schedules. The company has set the rule: "If an employee gets a day off during the week, then that person must have worked on the weekend." "If an employee works on the weekend, then that person gets a day off during the week."

Robert has never worked on weekends before but is considering doing that. However, Robert has heard many rumors that the company has violated the rule before. To verify whether the rule has been violated, Robert talks with four co-workers.

Each of the four cards below describes one of the four co-workers. One side of the card indicates whether the co-worker has worked on a weekend, and the other indicates whether that coworker has gotten a day off during the week. 